\title{
COMPARISON OF WIDAL AND TYPHOID IMMUNOGLOBULIN M AND IMMUNOGLOBULIN G IN RAPID AND EARLY DIAGNOSIS OF ENTERIC FEVER
}

\author{
SHARANYA $\mathrm{K}^{1 *}$, VINOD $\mathrm{K}^{2}$, LAKSHMI $\mathrm{K}^{1}$ \\ ${ }^{1}$ Department of Microbiology, Sree Balaji Medical College and Hospital (Bharath University), Chennai, Tamil Nadu, India. ${ }^{2}$ Department of \\ Anaesthesiology, Shri Sathya Sai Medical College and Research Institute, Thiruporur, Chennai, Tamil Nadu, India.
}

Email: sharuisalways@yahoo.com

Received: 11 August 2016, Revised and Accepted: 07 September 2016

\section{ABSTRACT}

Objective: Typhoid fever is one of the major public health problems in developing countries including India. A simple, reliable, rapid, and early diagnostic test has been one of the important needs of the clinicians. The present study was carried out to compare the Widal test and typhoid immunoglobulin M (IgM) and immunoglobulin G (IgG) rapid test in diagnosing of Salmonella typhi infection.

Methods: A total of 100 cases having clinical suspicion of typhoid fever and 40 controls (20 healthy persons and 20 non-typhoidal febrile patients) were studied. Participants were investigated by blood culture, clot culture, Widal test, and typhoid IgM and IgG rapid test, and the results were compared.

Results: Typhoid IgM and IgG test was positive for IgM in 70 cases and IgG for 6 cases of typhoid fever compared to Widal test which showed only 58 positive cases. The sensitivity, specificity, positive, and negative predictive value of typhoid IgM was found as $70 \%, 90 \%, 94.59 \%$, and $54.55 \%$, respectively. On the other hand, corresponding values for Widal test were $58 \%, 85 \%, 90.63 \%$, and $44.74 \%$, respectively.

Conclusion: In the present study, the typhoid IgM and IgG yielded remarkable high sensitivity and specificity to diagnose typhoid fever in the first week of illness, so it is recommended to use the test in small and less equipped laboratories as a complementary test to Widal.

Keywords: Widal, Typhoid immunoglobulin M/immunoglobulin G, Typhoid fever, Blood culture.

(C) 2016 The Authors. Published by Innovare Academic Sciences Pvt Ltd. This is an open access article under the CC BY license (http://creativecommons. org/licenses/by/4. 0/) DOI: http://dx.doi.org/10.22159/ajpcr.2016.v9s3.14648

\section{INTRODUCTION}

Enteric fever is a global health problem. Its real impact is difficult to estimate because the clinical picture is confused with other febrile infectious diseases. The incidence of typhoid fever has been estimated approximately 2.17 million cases with at least 217,000 deaths occurring worldwide annually [1]. The disease is endemic in the Indian subcontinent [2]. A delay in diagnosis and management may significantly increase the risk of adverse outcome and mortality [3]. Hence, an accurate diagnosis of enteric fever at an early stage is important not only for etiological diagnosis but also to identify the potential carriers and may be responsible for acute enteric fever outbreaks [4]. Although blood culture is the gold standard for the diagnosis of enteric fever, it is not routinely requested by physicians because it is expensive and there is delay in result of at least 2-3 days [5]. The Widal test has been used for almost 100 years and widely available in developing countries and is still regarded useful in endemic areas [6]. However, it becomes positive only in the second week of illness [7], and paired sera are required for confirmation of the diagnosis [8]. Hence, the limitation of the above traditional methods has prompted other novel tests to be developed. The typhoid immunoglobulin M (IgM)/immunoglobulin G ( $\operatorname{IgG}$ ) rapid test is also a new serologic test based on the lateral flow immunochromatographic principle. It detects the presence of specific IgM and IgG antibodies to Salmonella typhi lipopolysaccharide. The test becomes positive as early as in the first week of the fever; the results can be interpreted visually and available within 15 minutes. Hence, it provides an alternative for rapid and early diagnosis of typhoid fever.

\section{METHODS}

The study was designed as cross-sectional comparative study for 1 year. Relevant history, clinical findings, and laboratory records of every case were collected and recorded, and the data were analyzed using a computer program SPSS Version 20. The study population consisted of
100 clinically suspected typhoid fever cases and 40 controls comprising 20 healthy and 20 non-typhoidal febrile illness cases. 100 clinically suspected typhoid fever cases (irrespective of age and sex) were selected on the basis of following criteria of fever for $>3$ days, with no obvious focus of infection, abdominal discomfort, constipation or loose motion, coated tongue, toxic look, hepatomegaly, splenomegaly, relative bradycardia, rose spot, etc. [9].

Blood culture was done by conventional or traditional method using trypticase soy broth (TSB) with sodium polyanethol sulfonate. $5 \mathrm{ml}$ of collected blood for adult and $3 \mathrm{ml}$ of collected for pediatric patients were inoculated immediately into $50 \mathrm{ml}$ and $30 \mathrm{ml}$ TSB broth (which was brought to room temperature 30 minutes before inoculation), respectively. The inoculated bottle was inverted 3-5 times to mix blood with broth. Inoculated culture bottle was incubated at $37^{\circ} \mathrm{C}$ aerobically. Bottles were examined visually daily for growth. It was indicated by hemolysis of red blood cells, gas bubbles in the medium or turbidity in the broth. When macroscopic evidence of growth was apparent, a Gram-stained smear was done. In addition to daily visual examination, blind subculture from conventional bottle after the first $24 \mathrm{hrs}$ of incubation was performed aseptically removing a few drops of the wellmixed medium and spreading this inoculum onto MacConkey and Blood agar plates. The plates were incubated at $37^{\circ} \mathrm{C}$ aerobically for $24-48 \mathrm{hrs}$. Culture negative bottles were then reincubated for 5-7 days [10]. Suspected colonies were identified as $S$. typhi by Grams stain, motility test and by following biochemical tests including - oxidase test, triple sugar iron agar (TSI), citrate, indole and urease tests, and slide agglutination test with high titer sera.

For blood clot culture, a modification of method described by Escamilla et al. [11] was used. The clot was broken up with a sterile glass rod and added to bottle of $50 \mathrm{ml}$ bile broth. Streptokinase (100 units/ml) was added into the broth to facilitate lysis of the clot. Culture was incubated 
at $37^{\circ} \mathrm{C}$ for $24 \mathrm{hrs}$. At interval of 1,3 , and 7 days, subculture was done on blood and MacConkey agar non-lactose fermenting colonies from the MacConkey agar plates were identified by Gram's staining, oxidase test, conventional biochemical tests, and slide agglutination test using high titer antisera.

The Widal test was done by tube agglutination using various dilutions and significant titer was taken as 1:80 and above for T0 and 1:160 and above for TH [12].

The rapid test for detection of IgM and IgG antibody in patient's serum was done in all groups of cases and controls. The test is based on lateral flow immune-chromatographic principle. The device contains two test strips: One for IgM detection and another for IgG detection. The IgM strip consisting of a dried conjugate pad containing antihuman IgM conjugated with colloidal gold, a nitrocellulose membrane immobilized with $S$. typhi antigen lipopolysaccharide (LPS) at test line region " $\mathrm{T}$ " and a control line protein at control line "C." The IgG strip consisting of a dried conjugate pad containing protein A conjugated with colloidal gold, on a nitrocellulose membrane immobilized with $S$. typhi antigen LPS at test line region "T" and control line protein at control line region "C." When test specimen is applied into sample well(S) of the test device, the specimen migrate by the capillary action across the nitrocellulose membrane. If antibody to $S$. typhi is present in the specimen, it will react to the colloidal gold conjugate and makes an immune complex. The immune complex moves on the membrane and reacts with immobilized antigen of $S$. typhi resulting information of pink/purple line at "T" region. The test contains an internal inbuilt control which should exhibit a pink or purple line at " $\mathrm{C}$ " region. The result is invalid if pink/purple line at " $\mathrm{C}$ " is invisible.

About $5 \mu$ of specimen was added using micropipette into the S+B well or fill the provided disposable plastic dropper with the specimen up to the indicated mark on dropper and add into S+B well. Add 2 drops of buffer into S+B and wait for appearance of pink/purple lines in result window. Results were read within 15 minutes.

Positive result was observed as appearance of pink/purple lines at " $\mathrm{T}$ " and "C" region which indicates specimen has antibody to $S$. typhi. Negative result was observed as appearance of only one pink/purple line at "C" region which indicates that specimen has no antibody to $S$. typhi.

\section{RESULTS}

The present study was conducted among 140 participants. 100 were clinically suspected case of typhoid fever and 40 were age- and sexmatched healthy and sick controls. Out of 100 cases, 16 were culture positive for S. typhi, 58 were Widal positive, and rest of the 32 were clinically diagnosed typhoid fever, but blood culture and Widal test were negative. $70(70 \%)$ were typhoid IgM/IgG positive (Table 1). The rapid test was found to be highly significant than Widal test among clinically diagnosed typhoid fever $(\mathrm{p}<0.001)$.

The highest rate of blood culture positivity for S. typhi was found among 1-5 years of age group (16.66\%). Among the 32 cases, that were both blood culture and Widal test negative 6 cases were rapid test positive. Typhoid IgM/IgG was positive in $10(62.5 \%)$ out of 16 culture positive typhoid cases. The rapid test was also positive in $4(20 \%)$ out of 20 febrile controls. None of the healthy controls were positive by rapid test (Fig. 1). The Widal test was positive in $6(37.50 \%)$ out of 16 blood culture positive cases and in $52(61.90 \%)$ out of 84 culture negative typhoid cases. Out of 16 blood culture positive typhoid cases, only $6(37.50 \%)$ was Widal positive.

Out of 84 culture negative typhoid cases, $60(71.40 \%)$ were rapid test positive and $52(61.90 \%)$ positive for Widal. Among the non-typhoid febrile illness cases, 4 (20\%) were rapid test positive (2 were Salmonella paratyphoid A cases and the other 2 had respiratory and urinary tract infection).
Of the healthy controls, none were positive for typhoid IgM/IgG, but $2(10 \%)$ were positive for Widal test. The rapid test was more significant in both culture positive and culture negative cases than Widal test. Sensitivity and specificity of typhoid IgM/IgG among typhoid cases are shown in (Table 2). Accordingly, sensitivity and specificity were calculated as $70.00 \%$ and $90.00 \%$, respectively, for rapid test. The Widal test was positive in $58(58.00 \%)$ out of 100 typhoid cases, and among 40 controls, $6(15 \%)$ were positive and $34(85.00 \%)$ were negative Accordingly, sensitivity and specificity were calculated as $58.00 \%$ and $85.00 \%$, respectively. The sensitivity of rapid test was found to be higher than Widal test (70.00\% and $58.00 \%$ ) in the early serodiagnosis of typhoid fever, whereas the specificity was found to be $(90 \%$ and $85 \%$ ), respectively (Table 2 ).

\section{DISCUSSION}

Isolation of the causative agent by culture has remained the gold standard for diagnosis of typhoid fever. Blood culture has got a limited utility due to its low sensitivity. Although the Widal test has been used for more than a century in many developing countries, it is non-specific, poorly standardized, often confusing, and difficult to interpret [13]. Moreover, sharing of $\mathrm{O}$ and $\mathrm{H}$ antigens by other Salmonella serotypes and other members of Enterobacteriaceae makes the role of Widal test even more controversial in diagnosing enteric fever [14]. On the other hand, typhoid IgG/IgM is a new, inexpensive, and reliable serodiagnostic test recently available commercially that enables direct observation of antibody binding to antigen profiles. Keeping this in mind, this study was carried out in search of an appropriate replacement for Widal test.

In our study, 100 febrile patients clinically suggestive of typhoid fever were screened for isolation of $S$. typhi by blood culture and clot culture. Among them, $16(16 \%)$ were positive for S. typhi. This constituted

Table 1: Comparison of various diagnostic methods among clinically suspected typhoid cases

\begin{tabular}{lll}
\hline Test & Positive (\%) & Negative (\%) \\
\hline Blood culture $(\mathrm{n}=100)$ & $16(16)$ & $84(84)$ \\
Clot culture $(\mathrm{n}=100)$ & $16(16)$ & $84(84)$ \\
Widal $(\mathrm{n}=100)$ & $58(58)$ & $42(42)$ \\
Typhoid IgM/IgG $(\mathrm{n}=100)$ & $70(70)$ & $30(30)$ \\
\hline
\end{tabular}

IgG: Immunoglobulin G, IgM: Immunoglobulin M

Table 2: Comparison of results among Widal and rapid test

\begin{tabular}{lllll}
\hline Test & $\begin{array}{l}\text { Sensitivity } \\
\text { (\%) }\end{array}$ & $\begin{array}{l}\text { Specificity } \\
\text { (\%) }\end{array}$ & $\begin{array}{l}\text { PPV } \\
\text { (\%) }\end{array}$ & $\begin{array}{l}\text { NPV } \\
\text { (\%) }\end{array}$ \\
\hline Thyphoid IgG/IgM & 70 & 90 & 93.93 & 85.71 \\
Widal & 58 & 85 & 90.62 & 77.27 \\
\hline
\end{tabular}

IgG: Immunoglobulin G, IgM: Immunoglobulin M

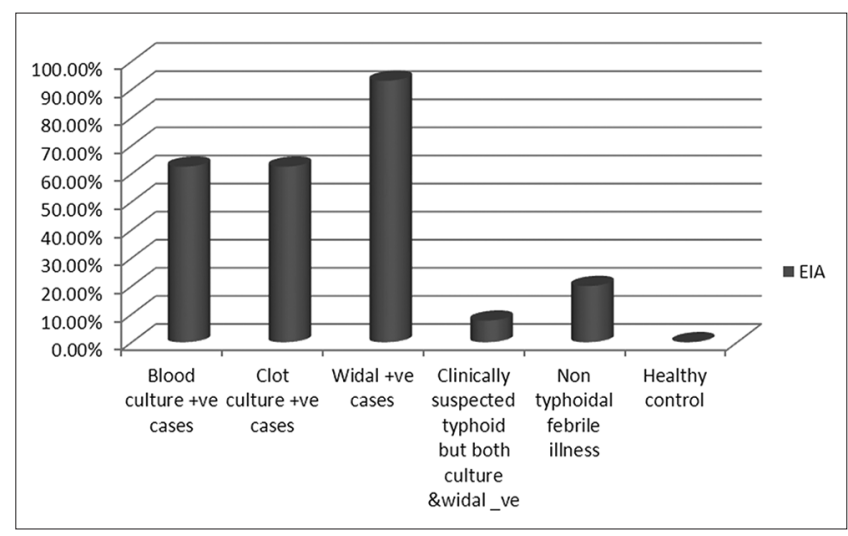

Fig. 1: Category-wise results of rapid test 
the bacteriologically proven enteric fever. The clot culture yielded a sensitivity of $100 \%$ when compared to blood culture in our study. A similar study by Simanjuntak et al. [15], Indonesia compared the sensitivities of whole blood and clot culture in 155 patients who had typhoid or paratyphoid fever, $S$. typhi, and S. paratyphi A was isolated from $98.7 \%$ blood culture and $94.8 \%$ clot culture positives with nearly equal sensitivity. The results of the above study correlated well with ours. Mantur et al. [16] did a similar study where the clot culture was found to be much more sensitive for Salmonella than whole blood culture. Bacterial growth was significantly faster in culture of blood clots compared to whole blood.

The remaining 84 patients were culture negative but clinically suggestive of typhoid fever. In our study, the sensitivity of Widal was $58 \%$ and specificity was $85 \%$ which was almost same when compared with the study of Mathew and Jobin [12], from Chennai where the sensitivity was $47.5 \%$ and specificity was $67.2 \%$. Widal test done on early phase of illness has shown limited diagnostic value because of its low sensitivity. Paired sera testing would be more advantageous than a single Widal test [12]. Another study also illustrated that a single Widal test is not diagnostic and four-fold rise in titer after an interval 7-10 days is more diagnostic for enteric fever [17]. In our study, among clinically suspected 100 enteric fever cases, 32 cases were both blood culture and Widal test negative. However, out of these 32 cases, 6 cases were rapid test positive.

In the present study, out of clinically diagnosed typhoid fever, $16 \%$ showed positive blood culture for $S$. typhi. Similar finding was also reported by Saha et al. [18] from Kolkata. They reported an isolation rate of 21.1\% and Hossain [19] from Bangladesh reported an isolation rate of $16.67 \%$. In contrast, Saha et al. [18] from Bangladesh and Jessudasen and Sivakumar [20] from India reported an isolation rate of only $8.40 \%$ and $6.97 \%$, respectively. The relative low sensitivity of the blood culture in diagnosis of typhoid fever attributes to the widespread and irrational use of antibiotics and the difficulties in obtaining large volume of blood for cultures from children $[7,21]$.

The most widely used serological test in typhoid fever is to detect antibody against $\mathrm{O}$ and $\mathrm{H}$ antigen of $S$. typhi by Widal test. In the present study, Widal test was carried out in a group of patients and controls. The cutoff value of Widal test was considered as 1:80 for T0 and 1:160 for TH [12]. Although Widal test usually becomes positive from the second week, in this study out of 16 culture positive typhoid patients, $6(37.77 \%)$ had an initial TO titer $>80$ and $\mathrm{TH}>160$ in the first week of illness.

A study done by Shukala et al., 1997 [22] found that $44.2 \%$ had TO titer of $>160$ in single sample collected in the early phase of illness from patients suspected to have typhoid in an endemic area of central India. These findings were most probably attributable to a hyperimmune or immunologically sensitized population which is continually exposed to S. typhi and other Salmonellae [23]. This observation is also of practical importance as second specimens are often not sent to laboratory. The results obtained are also of relevance to the concept that specimens which are taken in the first week of illness are of little use in the serodiagnosis of typhoid. The incidence of false-negative the Widal test among the bacteriologically proven cases of this study was 10 (62.50\%). This finding was higher than other studies which showed false negatives in Bangladesh as 11.3\% [24] in Iran as 24\% [25] and 6.9\% in Malaysian population [26]. Possible hypothesis put forward to explain this phenomenon was, prior use of antibiotics, the existence of less immunogenic strains of $S$. typhi and reduced immunity from severe nutritional hypoproteinemia [25].

Out of 20 non-typhoidal febrile cases, $4(20 \%)$ showed high titer in the Widal test. These findings were closely similar to the findings of Duthie and French [27]. They found 23\% false-positive results in the Widal test. Handojo et al. [28] in Indonesia also found 7\% non-typhoid fever cases showing a false positive for Widal test. In contrast, Pang and Puthucheary [29] found that 3\% of non-typhoidal fever gave a significant Widal reaction. This raised Widal titer in non-typhoidal febrile patients was perhaps due to the fact that these persons had been infected by $S$. typhi in the past as Salmonella agglutinating antibodies may show a non-specific raise as a result of non-typhoidal fever [29].

Out of 20 healthy controls, $2(10 \%)$ case was positive for TH (titer $>160$ ) our findings were almost similar to those of Saha et al. [25]. They reported $4.3 \%$ false positive out of 300 healthy Bangladeshi children who had a TH titers of $>160$. This raised TH titer among our healthy controls was probably due to previous exposure to $S$. typhi as typhoid is endemic in our region [25]. Antibodies to S. typhi specific LPS were detected in 70 sera by the rapid test typhoid IgG/IgM.

In our present study, it was found that typhoid $\operatorname{IgG/IgM~was~positive~in~}$ $70 \%$ out of 100 clinically suspected typhoid cases, whereas the Widal test was positive in only $58 \%$. These findings were almost similar with Bhutta and Mansurali [8] and Sherwal et al. [30]. They reported a similar rapid test positive $70 \%$ and $79 \%$, Widal positive $54 \%$ and $57 \%$, respectively, among clinically suspected typhoid fever.

In our study, it was found that typhoid IgG/IgM has sensitivity of $70 \%$. Our results were slightly lower than the findings of Sherwal et al. [30] from India, who reported a sensitivity $92 \%$ to a rapid test and Choo et al. [31], who found sensitivity of $90.3 \%$. Several studies have reported much higher sensitivity for rapid tests in diagnosing typhoid fever cases [20]. Jesudasson et al. [20] and Choo et al. [31] reported $100 \%$ and $98 \%$ sensitivity to rapid tests, respectively, in detecting enteric fever. This difference was probably due to the fact that in those studies unlike us, they have included all typhoid patients irrespective of duration of fever and result of the repeat tests.

In our study, typhoid IgG/IgM was found to have high specificity 90\%. In agreement with our finding, Bhutta and Mansurali [8] found 89\% specificity, Sherwal et al. [30] found 87.5\%, and Gopalakrishnan et al. [32] found $100 \%$ specificity of rapid tests in the diagnosis of enteric fever. In contrast, a study from Pakistan [8] reported a much lower specificity $(77 \%)$ of rapid test. This was due to a high rate $(23 \%)$ of positivity among non-typhoidal febrile patients. In our study, we got a positive predictive value of $94.59 \%$ and a negative predictive value $54.55 \%$.

\section{CONCLUSION}

Thus, this study shows that typhoid IgM/IgG procedure is more sensitive than the established Widal agglutination assay for providing evidence of infection with $S$. typhi. It can be performed in a single working day, in contrast to the Widal agglutination assay, which takes 2 days. We suggest that typhoid IgM/IgG should be considered as a viable alternative to the long established Widal agglutination assay. After analyzing the findings of the present study, it is suggested that though blood culture is gold standard for diagnosis of typhoid fever along with rising titer of Widal test, typhoid IgM/IgG with its higher sensitivity and specificity might actually be a practical alternative test for diagnosis of enteric fever. Further multicentric intensive research on typhoid IgM/IgG test is recommended.

\section{REFERENCES}

1. Crump JA, Mintz ED. Global trends in typhoid and paratyphoid fever Clin Infect Dis 2010;50(2):241-6.

2. Kothari A, Pruthi A, Chugh TD. The burden of enteric fever. J Infect Dev Ctries 2008;2(4):253-9.

3. Bhutta ZA. Impact of age and drug resistance on mortality in typhoid fever. Arch Dis Child 1996;75(3):214-7.

4. Parker MT. Enteric infections: Typhoid and paratyphoid fever. In: Collies L, Balows A, Suusman M, editors. Topley and Wilson's Microbiology and Microbial Infections. $8^{\text {th }}$ ed., Vol. 3. London: Arnold; 1990. p. 423-46.

5. Gasem MH, Dolmans WM, Isbandrio BB, Wahyono H, Keuter M, Djokomoeljanto R. Culture of Salmonella typhi and Salmonella 
paratyphi from blood and bone marrow in suspected typhoid fever Trop Geogr Med 1995;47(4):164-7.

6. Pang T, Puthucheary SD. Significance and value of the Widal tes in the diagnosis of typhoid fever in an endemic area. J Clin Pathol 1983;36(4):471-5.

7. Haque A, Ahmed J, Qureshi JA. Early detection of typhoid by polymerase chain reaction. Ann Saudi Med 1999;19(4):337-40.

8. Bhutta ZA, Mansurali N. Rapid serologic diagnosis of paediatric typhoid fever in an endemic area: A prospective comparative evaluation of two dot enzyme immunoassays and the Widal test. Am J Trop Med Hyg 1999;61(4):654-7.

9. Butler T, Scheld WM. In: Goldman L, Ausiello D, editors. Typhoid Fever in Cecil Text Book of Medicine. $22^{\text {nd }}$ ed., Vol. 2. Philadelphia, PA, Pennsylvania: Saunders, An Imprint of Elsevier; 2004. p. 1847-52.

10. Forbes BA, Sahm DF, Weissfeld AS. Blood Stream Infection in Bailey $\&$ Scott's, Diagnostic Microbiology. $11^{\text {th }}$ ed. St. Louis, Missouri, USA: Mosby, Inc.; 2002. p. 871-83.

11. Escamilla J, Santiago LT, Uylangco CV, Cross JH. Evaluation of sodium polyanethanol sulfonate as a blood culture additive for recovery of Salmonella typhi and Salmonella paratyphi A. J Clin Microbiol 1983;18(2):380-3.

12. Mathew R, Jobin SR. A comparative study on methods for diagnosis of enteric fever. Int J Curr Res Rev 2013;5(14):88-95.

13. Schroeder SA. Interpretation of serologic tests for typhoid fever. JAMA 1968;206(4):839-40.

14. Parry CM, Hien TT, Dougan G, White NJ, Farrar JJ. Typhoid fever. N Engl J Med 2002;347(22):1770-82.

15. Simanjuntak $\mathrm{CH}$, Hoffman SL, Darmowigoto R, Lesmana $M$, Soeprawoto, Edman DC. Streptokinase clot culture compared with whole blood culture for isolation of Salmonella typhi and S. paratyphi A from patients with enteric fever. Trans R Soc Trop Med Hyg 1988;82(2):340-1

16. Mantur BG, Bidari LH, Akki AS, Mulimani MS, Tikare NV. Diagnostic yield of blood clot culture in the accurate diagnosis of enteric fever and human brucellosis. Clin Lab 2007;53(1-2):57-61.

17. Conanan EC, Dayrit MM, Flores BB, Roa RR, Obenza J, Faraon AO, et al. Typhoid fever pseudo epidemic in Oroquieta city: Lessons in the inappropriate use of the Widal test. Field Epidemiol Train Program 1989;65:205-9.

18. Saha MR, Dutta P, Palit A, Dutta D, Bhattacharya MK, Mitra U, et al. A note on incidence of typhoid fever in diverse age groups in Kolkata,
India. Jpn J Infect Dis 2003;56(3):121-2.

19. Hossain MS. Comparitive Study of Widal Test and DOT Enzyme Immunoassay for Early Seri Diagnosis Typhoid Fever. (Thesis) Bangabandhu Sheikh Mujib. Bangladesh: Medical University Dhaka; 2001.

20. Jesudason MV, Sivakumar S. Prospective evaluation of a rapid diagnostic test typhidot ${ }^{\circledR}$ for typhoid fever. Indian $\mathrm{J}$ Med Res 2006;123:513-6.

21. Mohanty SK, Ramana KV. Single and unpaired sera tube Widal agglutination test in enteric fever. Saudi J Gastroenterol 2007;13(4):213

22. Shukala S, Patel B, Chitinnis DS. 100 years of Widal test and its re appraisal in an endemic area. Indian J Med Res 1997;105:53-7.

23. Senewiratne B, Senewiratne K. Reassessment of the Widal test in the diagnosis of typhoid. Gastroenterology 1977;73(2):233-6.

24. Saha SK, Ruhulamin M, Hanif M, Islam M, Khan WA. Interpretation of the Widal test in the diagnosis of typhoid fever in Bangladeshi children. Ann Trop Paediatr 1996;16(1):75-8.

25. Noorbakhsh S, Rimaz S, Rahbarimanesh AA, Mamishi S. Interpretation of the Widal test in infected children. Iran J Public Health 2003:32(1):35-7.

26. Malik AS, Malik RH. Typhoid fever in Malaysian children. Med J Malaysia 2001;56(4):478-90.

27. Duthie R, French GL. Comparison of methods for the diagnosis of typhoid fever. J Clin Pathol 1990;43(10):863-5.

28. Handojo I, Edijanto SP, Retnowati E, Salim SY. The Widal slide agglutination test (SAT) using antigen from locally prevalent Salmonella typhi as a diagnostic tool for typhoid fever. Folia Med Indones 2003;39(1):29-35.

29. Pang T, Pothocheary SD. False-positive Widal test in nontyphoid Salmonella infections. Southeast Asian J Trop Med Public Health 1989;20(1):163-4.

30. Sherwal BL, Dhamija RK, Randhawa VS, Jais M, Kaintura A, Kumar M. A comparative study of typhidot and Widal test in patients of typhoid fever. JIACM 2004;5(3):244-6.

31. Choo KE, Oppenheimer SJ, Ismail AB, Ong KH. Rapid serodiagnosis of typhoid fever by dot enzyme immunoassay in an endemic area. Clin Infect Dis 1994;19(1):172-6.

32. Gopalakrishnan V, Sekhar WY, Soo EH, Vinsent RA, Devi S. Typhoid fever in Kuala Lumpur and a comparative evaluation of two commercia diagnostic kits for the detection of antibodies to Salmonella typhi. Singapore Med J 2002;43(1):354-8. 